\title{
CONSIDERAÇÔES SOBRE O DESENVOLVIMENTO DO PENSAMENTO EDUCACIONAL ACERCA DA EDUCAÇÃO DO CORPO
}

\author{
Maria Teresa Martins Fávero ${ }^{1}$ \\ Geiva Carolina Calsa ${ }^{2}$ \\ Teresa Kasuko Teruya ${ }^{3}$
}

\begin{abstract}
RESUMO
O trabalho apresenta considerações sobre o desenvolvimento do pensamento educacional acerca da educação do corpo. O objetivo foi analisar as concepções sobre o corpo na cultura ocidental e as formas como estes pensamentos se manifestaram na prática educativa. A concepção de corpo na sociedade grega é um marco do desenvolvimento histórico cultural da humanidade. Pensadores como Locke, Rousseau, Kant, Dewey, entre outros refletiram sobre as questões do corpo em seus escritos sobre a educação. No período de Institucionalização da escola há um pensamento e educação do corpo com ênfase na superioridade da mente, marcado por idéias de disciplina, moral e higiene. A revolução industrial e o capitalismo promoveram mudanças na sociedade que influenciaram a forma de se pensar e de se educar o corpo. Na atualidade o dualismo não mais opõe a alma ao corpo, mais sutilmente opõe o homem ao corpo como se fosse um desdobramento. As reflexões acerca do tema em questão demonstram que até hoje o corpo ocupa um espaço secundário no contexto escolar, resultado da não superação das idéias cartesianas.
\end{abstract}

Palavras-chave: Corpo; Educação; Escola

\section{CONSIDERATIONS ON THE DEVELOPMENT OF EDUCATIONAL THOUGHT ABOUT BODY EDUCATION}

\begin{abstract}
The paper presents considerations regarding the development of educational thought about body education. The objective was to analyze the conceptions of the body in Western culture and the ways these thoughts were expressed in educational practice. The conception of the body in Greek society is a landmark of historical cultural development of mankind. Thinkers such as Locke, Rousseau, Kant, Dewey, among others, reflected on body issues in their writings on education. In the period of institutionalization of the school there is a thought and education of body with emphasis on the superiority of mind, marked by ideas of discipline, morals and hygiene. The industrial revolution and capitalism promoted changes in society that have influenced the way of thinking and to educate the body. Nowadays dualism no longer opposes soul to body, but contrasts subtly man to body as if it were an offshoot. The reflections on the subject in question show that up until now body occupies a secondary space in school context, as a result of the limits of Cartesian ideas.
\end{abstract}

Keywords: Body; Education; School 


\section{INTRODUÇÃO}

A preocupação com a educação do corpo, especialmente no contexto educacional é uma questão que precede a própria Pedagogia. As visões de corpo determinadas por cada momento histórico da humanidade influenciaram também a história da educação e, como conseqüência, a forma de se "educar" este corpo fora e dentro da escola.

A interdisciplinaridade entre educação e filosofia quando se fala sobre "corpo" é um desafio que se apresenta àquele que tenta escrever sobre o tema. A abordagem do desenvolvimento do pensamento educacional sobre a educação do corpo no processo histórico entendida neste ensaio parte da visão filosófica apontada por Cardim (2009) de que "se há criação de novos conceitos, é preciso compreender que é sempre um mesmo problema que está sendo retrabalhado pelos filósofos" (CARDIM, 2009, p.14). Assim, entende-se que a educação do corpo, e por conseqüência o "problema" corpo/mente passa por um processo de resignificação constante, influenciado pela cultura, política, economia e educação da sociedade na qual se insere. Não temos a intenção de aprofundar-nos sobre a "metafísica do corpo", nem mesmo sobre a "fenomenologia do corpo". Pretendemos retratar alguns momentos históricos na concepção do conceito de corpo que serviram de base para a educação da civilização ocidental. Nosso pressuposto teórico tem como princípio a visão filosófica do "corpo", apoiada nas idéias dos filósofos gregos, medievais, renascentistas e modernos, relacionadas às teorias educacionais fundantes da educação formal. Analisaremos a questão sobre um ponto de vista cronológico, entendendo que nem todos os espaços poderão ser ocupados diante da complexidade do tema, deixando ao leitor a tarefa de preenchê-los com leituras complementares.

\section{CORPO: FILOSOFIA E EDUCAÇÃO}

O pensamento filosófico nasce como forma de elaborar explicações racionais que possam fundamentar o discurso e o pensamento da origem e ordem de toda a realidade e do ser (CHAUÍ, 2002; MARCONDES, 2008). Compreender as práticas pedagógicas de intervenção pelo e sobre o corpo na atualidade, exige uma síntese das idéias filosóficas acerca deste conceito desde a Antiguidade.

No senso comum nomeamos "corpo" "às coisas que ocupam lugar no espaço (que possuem extensão), que nos rodeiam e que percebemos sensorialmente" (DUTRA, 2000, p.02). As várias abordagens científico-filosóficas buscam compreender e raciocinar sobre este conceito, procurando identificar e descrever-lhe os atributos distinguíveis. Desde a Antigüidade isto já se intentava o que permitiu o desenvolvimento de diversos questionamentos a respeito das atividades mentais, além das especulações sobre o funcionamento das estruturas corporais e sobre a relação da alma e do corpo.

A concepção de corpo na sociedade grega é um marco do desenvolvimento histórico cultural da humanidade e traz contribuições importantes a nossa discussão. A visão de corpo construída a partir da filosofia que surge no século V a.C. difere consideravelmente do pensamento grego no período homérico (CASTRO e LANDEIRAFERNANDEZ, 2011). Não há termos em Homero para estruturas da atividade mental comparável, como por exemplo, à nossas palavras "alma" ou "mente". Vernant (1998) descreve que na Grécia Homérica, o corpo era visto como um aglomerado de membros representados pelos movimentos (guya,) e pela força da musculatura (melea). A estrutura, tamanho e semelhança dos corpos eram atribuídas à palavra demas (SNELL, 2001). Segundo o autor, o vocabulário homérico apresenta-se geralmente mais concreto do que 
abstrato o que explicaria a ausência de um conceito elaborado na cultura grega homérica de corpo, por exemplo.

Herold Júnior (2008) escreve que no Período Homérico a vida era regida por valores eminentemente coletivos. As necessidades corporais eram pensadas para atender a estes valores. A força, a velocidade e a coragem eram atributos necessários para se vencer a batalha, eram virtudes fundamentais.
A própria prática dos homens se encarregava desta "pedagogia" do corpo, bem como de sua centralidade. Dessa maneira, em uma sociedade onde a vida dependia da força coletiva, onde a força física era prerrogativa óbvia a qualquer homem, ficava inviabilizada a necessidade da idéia de "preparar" (treinar), ou pelo menos, demonstrar a importância de formar o homem para a guerra, educando-o para tal (HEROLD JUNIOR, 2008, p. 36).

No Período da Antiguidade Clássica, vários filósofos discutiram as relações do corpo e da mente (alma): Heráclito de Èfeso (540 - 470 a.C.); Anaxímenes (nascido em torno de 560 a.C.); Diógenes de Apolônia (499 - 428 a.C.); Empédocles de Agrigento (495 - 435 a.C.); Teofrasto (372-282 a.C.); Alcmeon de Crotona, (500 - 450 a.C); Hipócrates (460 a. C.), entre outros, realizaram indagações a respeito do corpo e da alma, apesar de não haver indícios de oposição nas suas concepções fillosóficas, "pode-se dizer que nessa época a alma e o corpo não se opunham" (CARDIM, 2009, p.20). As separações e correlações entre a alma e o corpo receberam destaque nas obras de Platão (427-347 a.C.) e Aristóteles (384-322 a.C.).

Para Platão, o corpo era compreendido como veículo e prisão da alma, numa relação de subordinação. Em função disto, os gregos valorizavam uma educação que exaltasse a beleza e a perfeição, tanto para o corpo quanto para a alma. Eles acreditavam que, exercitando o corpo, promoviam benefícios também para a alma, pois essa prática proporcionava equilíbrio entre a coragem e a filosofia, além de desenvolver o espírito e a moral (CAMBI, 1999).

Os escritos de Platão recomendavam a educação para restabelecer e manter a saúde da alma (através da música e filosofia) e do corpo (ginástica nas suas várias modalidades de movimento). Uma boa educação age diretamente na manutenção ou no restabelecimento do equilíbrio por introduzir, desenvolver e consolidar a parte racional da alma no controle das demais.

Já na percepção de Aristóteles ${ }^{4}$ (384 a.C.-322 a.C.), a alma teria a forma do corpo (physis) e ambos atuariam em perfeita interação com o mundo a partir dos sentidos, da intuição e da consciência (psiquê). Portanto, Aristóteles reconhece o papel do corpo, não o considerando, como em Platão, prisão da alma. As experiências das sensações, descritas por Aristóteles trazem de volta o valor ao corpo, porém, ao apontar a existência de duas diferentes estruturas, mantém uma concepção de dicotômica mente/corpo (ROCHA, 2011).

Wegner Jaeguer (1995) na obra literária "Paidéia" destaca a influência do pensamento de Platão e Aristóteles na educação. De acordo com o autor, a "ginástica", como era chamada pelos gregos estava centrada sob os pilares de educação pensados e desenvolvidos por Platão e Aristóteles.

E os próprios exercícios de ginástica e trabalhos a que se entregar terão em mira antes de estimular o elemento impetuoso de sua natureza do que o mero vigor corporal; ao contrário dos atletas comuns, cujos exercícios e 
regime alimentar visam desenvolver os músculos. (PLATÃO, 1996, p. 73).

Para Zoboli (2007, p.51), esta idéia de Platão vem mostrar que a educação do corpo é uma prática voltada para a educação da alma. O corpo é só um meio de acessá-la e preservá-la.

Na Idade Média o culto ao corpo era visto como pecado. O cristianismo combatia a nudez, a ginástica e as atividades corporais. Guilhermetti (1990) ressalta que a rejeição ao corpóreo na sociedade feudal é de tal forma acentuada que até mesmo o trabalho perde a virtude, justamente por se caracterizar enquanto atividade física.

São Francisco de Assis, Santo Agostinho, São Tomás de Aquino, entre outros santos e filósofos desta época consolidaram a visão dualista de homem. O homem deveria buscar a salvação do espírito deixando de lado as práticas corporais que podem levar ao pecado, a luxúria e ao profano. $\mathrm{O}$ corpo era, portanto, foco de tensão entre o pecado e a salvação.

O modelo de educação deste período reforça a valorização do divino no intuito de humanizar os indivíduos. Primava-se pela educação da alma, pois enquanto homem "a característica de ter uma alma (essa alma ter sido criada por Deus) exige que todo empenho educativo dirija-se ao aprimoramento espiritual, religioso de cada um" (NAGEL, 1985, p. 04).

Vários autores renascentistas retrataram as formas de educar o corpo. Exemplos disto podem ser apreciados na obra de Erasmo de Roterdã (1978), que apresenta importantes reflexões sobre a educação dos gestos, da forma de se vestir, do andar, do olhar, das refeições, do portar-se à mesa, dos encontros, de como se dirigir aos mais velhos, do dormir e do jogo. Há também Montaigne, que escreve sobre a "natureza e o significado das expressões corporais como uma linguagem do corpo que projeta o indivíduo para fora de si mesmo e o expõe ao elogio ou à sanção do grupo" (NÓBREGA, 2005, p. 601).

O desenvolvimento técnico-científico desperta nos indivíduos um interesse pelo uso da razão científica como forma de conhecimento. Há um novo interesse pelas práticas corporais, não apenas por oposição ao cristianismo, mas pela necessidade de se fazer uso da nova ciência e técnica. Para Cardim (2009) neste cenário, Descartes (1596-1650) opera uma revolução filosófica semelhante à operada por Galileu Galilei (1564-1642) na ciência $^{5}$. O dualismo de forma e matéria, pensado pelos gregos sofreu a reformulação Tomista dando origem a "unidade" espírito e carne, levando ao desenvolvimento moderno e às filosofias de Bacon, Descartes, Locke, Kant, entre outras, cuja finalidade era complementar Platão. Descartes consagra e sistematiza o dualismo corpo/mente em suas obras Discurso do Método, Meditações Metafísicas, Tratado do Homem e na primeira parte das Paixões da Alma. A visão cartesiana trouxe consigo um vocabulário e um conjunto de categorias que permanecem vivos até hoje.

Junto com a tradição cartesiana, herdamos um vocabulário, e, como vocabulário, um determinado conjunto de categorias, dentro das quais estamos historicamente condicionados a raciocinar sobre esses problemas. (...) O vocabulário inclui uma série de oposições aparentes: 'físico' versus 'mental', 'corpo' versus 'mente', 'materialismo' versus 'mentalismo', 'matéria' versus 'espírito' (SEARLE, 1997, p.25).

Assim, Descartes concretiza a separação corpo/mente, mesmo suas idéias diferindo das idéias de Platão, Aristóteles e Santo Tomás de Aquino, pois nestas, embora corpo e 
alma fossem entidades distintas, um não existia sem o outro. Cardim (2009, p.33) concorda com esta diferença e admite que "a concepção cartesiana do corpo não é do estilo platônico", onde o sensível é oposto ao inteligível. "Ela também não é de estilo aristotélico", que vê na alma a forma do corpo. "A concepção cartesiana do corpo também não deriva da concepção tomista, para a qual seria preciso evocar a encarnação para justificar a idéia aristotélica [...]”.

[...] crê-se comumente que a separação instituída por Descartes entre alma e corpo, como entre duas substâncias diferentes, tenha tido como conseqüência o estabelecer a independência da alma em relação ao corpo. $\mathrm{Na}$ verdade, a sua primeira conseqüência foi a de estabelecer a independência do corpo em relação à alma e conclui: "Desse novo ponto de vista, o corpo aparece como uma máquina, uma máquina que caminha por si. (ABBAGNANO, 1982, p. 197)

Garanhani e Moro (2000, p.110) afirmam que resguardadas as profundas diferenças entre o Racionalismo idealista e o Empirismo, "pode-se dizer que é sob a influência destas matrizes teóricas que se inicia um processo de afirmação do corpo em seu aspecto científico, biológico e psicológico", levando a escola a iniciar um movimento de cuidados com o corpo e com a saúde por meio de cuidados e exercícios físicos. Como afirma Herold Junior (2012, p.28) há "um fortalecimento das inquietações educacionais que sublinhavam a dimensão corpórea do homem". Dentre muitos que poderiam ser citados, Locke e Rousseau por meio da ciência empírica, inauguraram mais uma etapa no processo de se pensar o corpo. Da Mata (1998, p.40) esclarece que para estes autores "a disciplina do corpo corrobora com a do espírito e vice-versa". O corpo não é mais fonte de pecado, ele é necessário à vida em sociedade e para tanto deve ser preparado por meio de exercícios. Porém, o autor escreve que as semelhanças param por aí.

O homem de Locke é o homem de negócios. O de Rousseau é o homem político (o cidadão). A diferença na concepção de homem faz com que os preceitos sobre educação do corpo sejam semelhantes, mas excludentes. Para um, o importante é a defesa da liberdade individual para aquisição de riquezas no mundo da competição e da conquista da propriedade privada; para o outro, o importante é a liberdade individual limitada pela vontade e pela coletividade, que tem por pressuposto uma igualdade moral estabelecida pela convenção social. Embora o método seja semelhante, o objetivo final a que se propõem é oposto (DA MATA, 1998, p.45).

A educação do corpo em Locke buscava o rigor corporal como base para o desenvolvimento da razão e da moral, possibilitando o autocontrole individual apreendido pela prática, cujo objetivo era preparar o homem de negócios. Rousseau, por sua vez, fala sobre a educação partindo do corpo: "Cultivai a inteligência dos vossos alunos, mas cultivai, antes de tudo, o seu físico, porque é ele que vai orientar o desenvolvimento intelectual. Fazei primeiro vosso aluno são e forte para poder vê-lo inteligente e sábio" (ROUSSEAU, 1992, p. 111). O objetivo de Rousseau é o desenvolvimento natural do futuro cidadão.

Ambos retratam o pensamento Iluminista da época ao propor o desenvolvimento do homem por meio da experiência e da prática de exercícios físicos que promovam a disciplina do corpo e da alma. Ao pensar uma educação que contemple o corpo, eles se 
contrapõem ao pensamento clássico e feudal onde essa união era impossível. Para Da Mata (1998), na visão de Rousseau e Locke, ainda que corpo e mente continuem separados, neste momento admite-se que ambos possam agir juntos no aprimoramento do ser humano, pois as percepções, os sentidos, os membros do corpo, "são os instrumentos utilizados pela inteligência para a criação de um mundo melhor aqui mesmo, na terra" (p.42).

Ainda nesta perspectiva, Immanuel Kant (1724-1804) escreve sobre a problemática dicotômica corpo/alma, afirmando que a mesma não tem sentido, pois "estão fora do campo do conhecimento humano" (op. cit. p.48). Assim, não faz sentido questionar a natureza última ou essência dos fenômenos mentais e físicos, algo que ultrapassa a capacidade de conhecimento.

Em seus estudos Kant aponta três períodos pelos quais se processa a educação: a educação do corpo ou física, a educação intelectual e a educação moral. No texto kantiano Sobre a pedagogia, que trata da educação, a parte da Educação Física, que discorre sobre os cuidados com o corpo, tem como aspecto principal a disciplina e as regras na vida do ser humano. A Educação Física, "consiste propriamente nos cuidados materiais prestados às crianças ou pelos pais, ou pelas amas de leite, ou pelas babás" (KANT, 2002, p. 37). Em a cultura da alma, um segundo momento da Educação Física, que Kant chamou de educação intelectual, ele ressalta que a formação da alma e do corpo é física, e deve-se cultivá-las para impedir que se corrompam mutuamente e buscar que a arte aporte algo tanto àquele como a esta. Pode-se, portanto, em um certo sentido, qualificar de física tanto a formação da alma quanto a do corpo (KANT, 2002, p. 59).

O processo de escolarização iniciado no século XV e XVI a partir da instauração do modelo produtivo capitalista marca a individualização da sociedade. As idéias e concepções filosóficas e pedagógicas que se desenvolveram "a partir do século XIV na Europa e que forneceram em sentido amplo o modelo de organização e funcionamento da escola [...]", definindo-a como um importante espaço onde se ditam e efetivam "[...] as estratégias de regulação e controle sobre a pessoa pela via do controle do corpo e dos gestos" (NUNES PINTO, 2002, p. 26). As preocupações com o corpo apontadas pela filosofia até então, passam a fazer parte das preocupações e projetos educacionais, perdendo seu caráter eminentemente antropológico. A escola passa a ser um dos locais responsável por "educar" o corpo ${ }^{6}$. Comenius $(1592-1670)$, considerado o pai da pedagogia, se propôs a criar métodos para tornar a aprendizagem escolar eficaz e atraente, mais rápida e segura, num discurso científico que desqualifica a família no tocante a educação do corpo e do espírito.

Para Taborda de Oliveira (2009, p.140), a idéia de educação do corpo instituída na escola estava marcada por representações de caráter religioso que só seriam extintas por volta do final do séc. XIX. Os programas da disciplina de Higyene, que ofereciam noções gerais sobre o asseio, a alimentação, o sono, o hábito dos exercícios físicos etc. apresentavam um caráter utilitário aos exercícios corporais, o que marcaria inclusive, o surgimento da Gymnastica como disciplina escolar. No processo de instituição da escolarização o corpo passa a ser motivo constante de preocupações. Seja no sentido de fortalecer o movimento operário ou o processo de industrialização, seja pela necessidade de saneamento físico e moral da sociedade.

Embora as discussões acerca do desenvolvimento do pensamento educacional sobre a educação do corpo estivessem presentes desde o início da Modernidade, somente tiveram seus conceitos e idéias incorporados enquanto disciplina /atividade a partir do século XIX, na Europa, sistematizadas como práticas corporais cujo nome era Ginástica (Gymnastica) ${ }^{7}$. Soares (2002) define que o termo Gymnastica abarcava uma enorme quantidade de práticas corporais, como exercícios militares de preparação para a guerra, jogos populares e da 
nobreza, acrobacias, saltos, corridas, equitação, esgrima, danças e canto. Era preciso perpetuar valores como a disciplina, a moral e a saúde. Mas, a Gymnastica escolar ao mesmo tempo em que sistematiza a educação do corpo fragmenta o conhecimento com interpretações do tipo teoria e prática, sala e pátio, reforçando a já conhecida separação do corpo (que executa) e da mente (que pensa).

\begin{abstract}
A incorporação da Ginástica na educação escolar determinou lugares e horários para o corpo e um parcial isolamento dessa dimensão da vida escolar. Os lugares delimitados para o corpo foram os espaços amplos ao ar livre e/ou as quadras, ginásios, pátios externos das escolas, longe das salas de aula e dos espaços considerados, realmente, sérios e produtivos. Seu tempo, fixado na maioria das vezes, em duas ou três horas semanais, carga horária menor que aquela reservado a outras disciplinas. Ali, o corpo foi concebido e tratado, hegemonicamente, como res extensa, ou seja, como extensão divisível em partes perfeitamente localizáveis em sua anatomia, que por sinal foi comparada à de uma maquinaria (NUNES PINTO, 2002, p.88).
\end{abstract}

O lugar do corpo na escola é definido, portanto, tal qual o lugar dado ao corpo pela humanidade, um local secundário, separado daquele destinado as atividades intelectuais. Segundo Bracht (1999), nestes moldes, a educação do corpo vai apoiar-se na idéia de superioridade da esfera mental ou intelectual. A razão é identificada como condição essencial que defini o ser humano. "O corpo deve servir. O sujeito é sempre razão, ele (o corpo) é sempre objeto; a emancipação é identificada com a racionalidade da qual o corpo estava, por definição, excluído" (p.70).

O modelo de Escola Tradicional entra em crise como conseqüência da morte da sociedade tradicional, pelo advento da sociedade industrial. Além disso, a opressão sofrida pela classe operária, o aumento da população urbana, a necessidade de oposição ao modelo de educação tradicional entre outras coisas fez surgir o movimento de renovação denominado Escola Nova. Este movimento alcança rapidamente quase todos os países da Europa, passando a transitar de ensaios dispersos e experiências de inspiração pessoal para uma fase de organização fundada em estudos sistemáticos.

Para Nóbrega (2005) no movimento escolanovista o discurso do corpo é fundamentado na instrumentalidade, na disciplina e na aprendizagem do respeito às normas de convívio em sociedade, trabalhadas por meio do jogo como elemento fundamental de uma pedagogia ativa. A cultura do corpo faz parte do ideário da Escola Nova. "Nela, a cultura do corpo é assegurada pela ginástica natural e pelas viagens a pé ou de bicicleta, e acampamentos e tendas" (MANACORDA, 1999, p.311).

As obras dos inspiradores deste movimento atribuem importância à educação do corpo, como por exemplo: Claparéde (1823-1940), Decroly (1871-1932), Freinet (1896 1966) e principalmente John Dewey (1859-1952), cujos primeiros trabalhos Pedagógicos repercutiram de forma notável.

Dewey fez vários apontamentos sobre o corpo e a educação, inclusive sobre a problemática dualista. Para este filósofo é na modernidade que "mente e matéria se colocaram uma em oposição a outra [...]" (DEWEY, s.d., p.251, apud ABREU E HAROLD JUNIOR, 2009, p.31). Dewey procurou apontar falsidade do problema retratando-o historicamente. Ao fazer a análise do pensamento antigo, o filósofo parte da tradição idealista de Platão, observando que mesmo os gregos considerando a alma como o elemento que caracterizava a vida, estes prestavam grande atenção ao corpo humano. Esta forma de pensar dos gregos sofre modificações na Idade Média, quando o corpo passa a ser 
considerado lugar de paixões e luxúria. Já na Idade Moderna há uma tentativa de reconciliação nas posições expressas pelos pensadores da antiguidade e da idade média, mediante a reconstrução dos conceitos de experiência e de razão. Dentro desta perspectiva, Dewey, como figura central do pragmatismo, pois deixando de lado racionalistas e empiristas, acredita que a mente não é algo passivo onde se deposita o conhecimento, nem a razão uma faculdade superior e isolada que formule conceitos. Os conceitos e categorias resultam da percepção das conexões e coordenações dos elementos constitutivos dos processos de experiência. Abreu e Herold Júnior (2009) destacam que para Dewey critica a escola tradicional por manter as crianças imóveis, sentadas e enfileiradas uma atrás das outras, desconsiderando assim a importância da experiência prática para a criança.

Dewey afirma que na escola tradicional, o aluno chega com um "corpo saudável" e uma "mente mais ou menos predisposta", tendo apenas o primeiro acesso às estruturas escolares. Ou seja, a escola tradicional, ao valorizar o intelectualismo, a imobilidade, a desconsideração do tempo presente em nome do tempo futuro, acaba por inviabilizar justamente aquilo que era seu objetivo principal: o desenvolvimento intelectual (ABREU E HAROLD JUNIOR, 2009, p.37).

Dewey critica a filosofia dualista afirmando que esta não valoriza a atividade corporal como instância cognitiva, classificando-a na maioria das vezes como irrelevante para os processos cognitivos. Essa visão mecanizada, dualista e racionalista de corpo praticada pela pedagogia Tradicional é o oposto da proposta de Dewey, cuja prática estabelece múltiplas associações e interdependências entre as atividades mentais e corporais (dos órgãos dos sentidos, do cérebro, dos diversos órgãos, etc.) que resultam de e produzem os diferentes processos cognitivos.

Apesar das idéias inovadoras do movimento escolanovista, interpretações equivocadas da teoria de Dewey provocaram confusões e controvérsias, gerando um desconforto que levou ao abandono da proposta por parte dos educadores. Porém, como bem nos lembra Saviani (2008, p.64), "o fracasso da escola nova, não invalida, entretanto, as críticas formuladas ao intelectualismo pedagógico".

A partir do século XX as normas, os padrões e as regras sociais impostos pela sociedade capitalista fazem do corpo um objeto mecânico, fruto de conhecimento biológico e fisiológico. As novas tecnologias de produção em massa homogeneízam gestos e atitudes, que acabam por influenciar a educação do corpo. O advento do capitalismo vai impondo, pouco a pouco, uma idéia de corpo como ferramenta através da qual se obtém lucro. Nesse cenário, Foucault (1987) destaca que a Instituição Escolar visa colocar o sujeito a mercê da ordem vigente, cujo objetivo é fabricar "corpos dóceis" e "úteis" (FOUCAULT, 1987).

Foucault descreve o corpo como peça central da modernidade, sem a qual o poder não teria condições de ser exercido. Para este autor, modernidade e "disciplinarização" do corpo são correspondentes, visto que ao descrever o funcionamento da sociedade moderna,a partir do final do século XVIII, Foucault desvendou o funcionamento de uma série de dispositivos disciplinares presentes no interior das instituições que tomaram o corpo como objeto de sua ação (CÈSAR, 2010, p. 163).

O objetivo é educar o corpo conforme os preceitos e normas que figuram a cada momento. O corpo modificado conforme o gosto do dia pode expressar adaptação, consumo, utilidade, erotismo, etc. Para que isto se concretize Soares (2006) no Prefácio da 
obra intitulada Educação do Corpo na Escola Brasileira afirma que "como lugar visível e como registro da cultura, os corpos e suas distintas expressões são objetos de constante intervenção do poder [...]" e acrescenta que as variadas formas de intervenção são "forjadas por inúmeras técnicas que são aprimoradas para incidir sobre os corpos", levando a práticas sociais indesejadas, ao que poderíamos chamar de "educação do corpo [...]". Soares (2002) chama isto de "pedagogia do corpo" que tem como proposta apresentar "um homem novo em sua aparência, linguagem e sentimentos, dentro de um tempo e de um espaço remodelados" (p.28).

As pedagogias do corpo podem ser definidas como práticas educativas que, tomam para si, a responsabilidade de intervir sobre o corpo individual visando produzir o indivíduo objetiva e subjetivamente apto às condições materiais de vida e às relações sociais capitalistas. Essas pedagogias não se constituíram como sistemas isolados das dimensões mais amplas da formação humana; ao contrário, estão presentes - de forma oculta ou não - no contexto ampliado das teorias e das práticas educacionais, constituindose como técnicas disciplinares (NUNES PINTO, 2002).

Acontece um "despertar de um interesse com a aparência do corpo, como sinônimo de felicidade e bem estar físico e social". Essa preocupação leva os sujeitos a educarem-se através modelos estereotipados que produzem uma dominação sutil. O corpo está atrelado aos valores comerciais desenvolvidos pela grande Indústria. "o corpo é coisificado pelo capitalismo (...) como uma entidade observável por via empírica, que referenda a continuidade de uma ordem econômica barbárica que impede o livre desenvolvimento do homem social" (FREITAS, 1994, p.37).

Para Almeida (2005), diferente de outros momentos da história onde a forma de educar o corpo se relaciona com a estrutura social vigente, na modernidade ela apenas reproduz o sistema político e econômico vigente, "o que está em questão é a perpetuação do sistema e não a construção de uma concepção de corpo que contribua para a emancipação do sujeito" (p.86).

A dualidade corpo e alma continuam presentes, atuando na base do pensamento educacional, só que agora com outros entendimentos e implicações, conforme afirma Le Breton:

O dualismo da modernidade não mais opõe a alma ao corpo, mais sutilmente opõe o homem ao corpo como se fosse um desdobramento. Destacado do homem, modulado conforme o gosto do dia, o corpo se equivale ao homem, no sentido em que, se modificando as aparências, o próprio homem é modificado (2006, p. 87)

A afirmativa de Foucault de que para se pensar a educação do corpo é preciso ter em mente que "cada época elabora sua retórica corporal". Portanto, cada sociedade imprime no corpo a sua forma, o seu modelo, modificando-o e modificando-se por conseqüência.

\section{CONSIDERAÇÕES FINAIS}

A cada momento histórico a sociedade concebe uma configuração de corpo distinta, que influencia a educação e é influenciada pela mesma. Assim, é válido ressaltar que as diversas concepções acerca da forma de se pensar e de se educar o corpo foram constituídas historicamente e, portanto, devem ser lidas a partir destes contextos. $\mathrm{O}$ pensamento de Platão e Descartes sobre a dualidade corpo e mente deve ser compreendido 
no contexto cultural da época em que foram propostos, mas não podem ser aceitos como "verdade" a ser praticada na sociedade em que vivemos. Uma sociedade moderna deve superar tais concepções em busca da emancipação do corpo. Como afirma Tuleski (2007, p.05) "a superação de tal cisão no mundo das idéias está condicionada à superação dessa dicotomia na realidade objetiva, que seria resolvida com a superação do materialismo mecanicista pelo materialismo histórico dialético"

Os filósofos gregos da Antiguidade Clássica ao pensar o corpo conceberam-no como forma e matéria, inaugurando a visão dualista que mais tarde seria modificada pelos Tomistas, dando origem ao pensamento moderno de Descartes, Bacon, Kant, Locke. Este pensamento tinha em sua essência a função de complementar as idéias de Platão por meio da pesquisa, da descoberta, da experimentação em face da evolução da sociedade e dos conhecimentos humanos. Retomando o que afirmamos no principio deste trabalho, "se há criação de novos conceitos, é preciso compreender que é sempre um mesmo problema que está sendo retrabalhado pelos filósofos" (CARDIM, 2009, p.14).

John Dewey afirma que as filosofias são, em essência, teorias gerais de educação. Nesse sentido, a instituição e sistematização da escola - peça central do processo educacional - favorece a transmissão destas concepções filosóficas ampliando a visão de mundo, de homem e de corpo presente historicamente na sociedade. As teorias educacionais conceberam o desenvolvimento do pensamento da educação do corpo ao longo dos séculos mantendo a visão dicotômica corpo/mente. Além deste aspecto, a educação formal passou a privilegiar o desenvolvimento de um (pensamento) sobre o outro (ação), instituindo o intelectualismo pedagógico.

A educação enquanto espaço de aplicação da filosofia, ao mesmo tempo em que se constitui campo de reelaboração e revisão destas, pode perpetuá-las enquanto modos de se conceber a educação, no caso deste trabalho, a educação do corpo.

Com a modernidade, o processo de industrialização modificou as formas de se conceber o homem e a sociedade, as teorias educacionais foram adaptadas para atender as novas formas de trabalho. Apesar dos avanços técnicos, científicos e educacionais a filosofia platônica continuou a dominar a educação e a sociedade. $\mathrm{O}$ dualismo atual se apresenta multiplicado em autoridade e liberdade, disciplina e autonomia, corpo e espírito, teoria e prática, fazeres e saberes, etc. Estas dicotomias impedem a construção de uma sociedade democrática.

$\mathrm{Na}$ atualidade as deformações geradas pelo dualismo levam a um individualismo exacerbado, enquanto que o progresso material tem levado ao homem a um processo de dominação e não de emancipação. O corpo moderno é um corpo preso a padrões estereotipados, dominado por modismos e consumos. Nesse sentido, é preciso pensar a educação - e educação do corpo - como forma de romper com o antigo dualismo num processo de construção e desenvolvimento de um ser único, buscando superar as dicotomias expressas na sociedade atual como divisão entre pensar e o fazer nos modos de trabalho, entre interesses individuais e sociais e entre classes.

\section{REFERENCIAS}

ABBAGNANO. Dicionário de Filosofia. São Paulo: Ed. Mestre Jou, 1982.

ABREU, Mariclaudia Aparecida; HEROLD JUNIOR, Carlos. Inteligência, Corpo e Educação Física no pensamento educacional de John Dewey. Revista HISTEDBR Online, Campinas, n.33, p.23-41, mar.2009 - ISSN: 1676-2584 
ALMEIDA, Claudia Regina. Corpos suspensos e emoldurados:Arquétipos de uma educação danificada. 2005. 118 f. Dissertação (Mestrado em Fundamentos da Educação). Universidade Estadual de Maringá. Maringá, Paraná. 2005.

BRACHT, Valter. A constituição das teorias pedagógicas da Educação Física. Cadernos Cedes, ano XIX Número 48, Agosto de 1999.

CAMBI, F. História da pedagogia. São Paulo: Editora da Unesp, 1999.

CARDIM, Leandro Neves. Corpo. Col. Filosofia Frente \& Verso. São Paulo: Globo, 2009.

CASTRO, F. S. e LANDEIRA-FERNANDEZ, J. Alma, Corpo e a Antiga Civilização Grega: As Primeiras Observações do Funcionamento Cerebral e das Atividades Mentais. Psicologia: Reflexão e Crítica, 24(4), 798-809, 2011.

CÉSAR, Maria Rita de Assis. A (des)educação do corpo. Corpos contemporâneos e lugares da transgressão. Vivência. n.35, p. 161-168, 2010.

CHAUÍ, Marilena. Convite à Filosofia. São Paulo: Ática, 2002.

DA MATA, Vilson Aparecido. Da força física à estética corporal: As mudanças nas relações sociais retratadas no corpo. Revista de Educação Física/Uem 9(1):35-43, 1998.

DUTRA, Lucas Vieira. O Dualismo Mente-Corpo: Implicações para a prática da atividade física. 1996. 59 f. Dissertação (Mestrado em Ciências da Motricidade). Instituto de Biociências do Campus de Rio Claro, Universidade Estadual Paulista, Rio Claro, São Paulo: CopyMarket.com, 2000.

FREITAS, Francisco Mauri de. O corpo e o filósofo - temas proibidos. Vitória: Centro de Educação Física e desporto da UFES, 1994.

FOUCAULT, M. Vigiar e punir: nascimento da prisão. Petrópolis: Vozes, 1987.

GARANHANI, Marynelma Camargo; MORO, Vera Luzia. A escolarização do corpo infantil: uma compreensão do discurso pedagógico a partir do século XVII. Educar em Revista, Curitiba, n.16, p. 109-119, 2000.

GUILHERMETTI, P. Do corpo medieval ao corpo moderno. Motrivivência. Rio de Janeiro, p.16-18, 1990.

HEROLD JUNIOR, Carlos. Corpo no trabalho e corpo pelo trabalho: perspectivas no estudo da corporalidade e da educação no capitalismo contemporâneo. Trab. Educ. Saúde, Rio de Janeiro, v. 10 n. 1, p. 11 35,mar./jun.2012.

HEROLD JUNIOR, Carlos. A educação física na história do pensamento educacional: apontamentos. Guarapuava: Unicentro, 2008.

JAEGER, Wegner. W. Paidéia: a formação do homem grego. Tradução de Artur M. Pereira. 3 ed. São Paulo: Martins Fontes, 1995.

KANT, I. Sobre a pedagogia. Trad. do alemão de Francisco Cock Fontanella. 3. ed. Piracicaba: Unimep, 2002.

LE BRETON, D. A sociologia do Corpo. Petrópolis: Vozes; 2006.

MANACORDA, M. A. História da educação: da antiguidade aos nossos dias. 7. ed. São Paulo: Cortez, 1999. 
MARCONDES D. Iniciação à história da filosofia: dos Pré-Socráticos a Wittgenstein. Rio de Janeiro: Jorge Zahar, 2008.

NAGEL, Lízia H. Avaliação, sociedade e escola. Curitiba: SEED, 1986.

NÒBREGA, Terezinha Petrucia da. Qual o lugar do corpo na educação?

Notas sobre conhecimento, processos cognitivos e currículo. Educ. Soc., Campinas, vol. 26, n. 91, p. 599-615, Maio/Ago. 2005 Disponível em: http://www.cedes.unicamp.br

NUNES PINTO, Rubia-Mar. Os professores e a produção do corpo educado: o contexto da prática pedagógica. 2002. 148 f. Dissertação (Mestrado em Educação). Universidade federal de Goiás. Goiânia/GO: [148], 2002

PlATÃO. A República. Trad. Maria Pereira. $8^{\text {a }}$ edição Lisboa: Calouste Gulbenkian. junho/1996.

ROCHA, Stéfanie da Cunha - Experiência do corpo: Mundo, arte, ensino. 2011. 79 f. Trabalho de Conclusão de Curso (Licenciatura em Artes Plásticas). Universidade Federal de Santa Catarina. Florianópolis, Santa Catarina. 2011.

ROUSSEAU, J. J. Emílio, ou, Da Educação. Tradução Sérgio Milliet. Rio de Janeiro: Bertrand Brasil, 1992. 581 p. Tradução de: Émile ou de l'éducation.

SAVIANI, Dermeval. Educação Brasileira: estrutura e sistema. $10^{\mathrm{a}}$ ed. Campinas: Autores Associados, 2008.

SEARLE, John R. A Redescoberta da Mente. São Paulo: Martins Fontes, 1997.

SNELL, B. A cultura grega e as origens do pensamento europeu. São Paulo: Perspectiva, 2001.

SOARES, C. L. Imagens da educação no corpo: estudo a partir da ginástica francesa no século XIX. Campinas: Autores Associados, 2002.

Prefácio.In: TABORDA DE OLIVEIRA, Marcus Aurélio. Educação do corpo na escola brasileira. Campinas: Autores Associados, 2006.

TABORDA DE OLIVEIRA, Marcus Aurélio. Saberes e práticas sobre a educação do Corpo Infantil na instrução pública primária nos anos Finais do século XIX no Brasil. Sarmiento. n.13, pp. 131-149; 2009.

Educação do corpo na escola brasileira: Teoria e História.

In: Educação do corpo na escola brasileira. Campinas: Autores Associados, 2006.

TULESKI, Silvana Calva. A Unidade Dialética entre Corpo e Mente na Obra de A. R. Luria: Implicações para a Educação Escolar e para a Compreensão dos Problemas de Escolarização. 2007. Tese (Doutorado em educação) Programa de Pós-Graduação da Faculdade de Ciências e Letras de Araraquara, Araraquara, São Paulo, 2007.

VERNANT, J. P. As origens do pensamento antigo. Rio de Janeiro, RJ: Bertrand Brasil, 1998.

ZOBOLI, Fábio. A episteme de cisão corpo/mente: As práxis da educação física como foco de análise. 2007. 212 f. Tese (Doutorado em Educação). Programa de Pós-Graduação em Educação da UFBA. Universidade Federal da Bahia. Salvador, Bahia. 2007 
${ }^{1}$ Professora do Departamento de Educação Física da UNESPAR/Campus de Paranavaí. Graduada em Educação Física pela Universidade Estadual de Maringá. Mestre em Educação pela Universidade Estadual de Maringá. Doutoranda do Programa de Pós-Graduação em Educação da Universidade Estadual de Maringá DTP/UEM. Email: leomate@uol.com.br

${ }^{2}$ Professora Adjunta do Departamento de Teoria e Prática da Educação da Universidade Estadual de Maringá DTP/UEM. Doutora em Educação pela Universidade Estadual de Campinas (2002). Coordena o Grupo de Estudos e Pesquisa em Psicopedagogia, Aprendizagem e Cultura - GEPAC/UEM. Email: gccalsa@hotmail.com

${ }^{3}$ Professora Associada do Departamento de Teoria e Prática da Educação da Universidade Estadual de Maringá DTP/UEM. Doutora em Educação pela Universidade Estadual Paulista Júlio de Mesquita Filho (1995) Coordena o Grupo de Estudos e Pesquisa em Psicopedagogia, Aprendizagem e Cultura GEPAC/UEM. Email: tkteruya@uem.br

${ }^{4}$ Para averiguar as diferenças básicas entre as filosofias de Platão e Aristóteles, os seguintes autores podem ser de utilidade: O'Connor (1974), Cresswell (1971) e Feibleman (1973).

5 Para o autor (2010, p.29) "ambas as concepções influenciam radicalmente a compreensão que o homem faz de si mesmo, assim como abrem um novo especo epistemológico e moral".

6 A educação do corpo antes da sistematização escolar (Gymnastica) era vivenciada pelo processo de endoculturação: aprendizagem e educação de uma cultura, desde a infância até a idade adulta. Através do qual um grupo social aos poucos socializa, em sua cultura, os seus membros, como tipos de sujeitos sociais (BRANDÃO, 1985).

${ }^{7}$ Entre as formas de se conceber a educação do corpo na escola estão os saberes elementares, na expressão de Hebrard (1990), a Gymnastica, a Hygiene, os Trabalhos Manuaes, as Prendas Domésticas, os Exercícios Militares, a Educação Física, a História Natural, o Canto Orfeônico, entre outros.

Recebido: fevereiro-14 $\quad$ Aprovado: $\quad$ março-15 